\title{
A ARGUMENTAÇÃO NA LÍNGUA COMO SUBSÍDIO PARA AVALIAÇÃO DE LEITURA E PRODUÇÃO DE TEXTOS DISSERTATIVO-ARGUMENTATIVOS
}

\author{
ARGUMENTATION WITHIN LANGUAGE AS SUBSIDY FOR THE \\ EVALUATION OF READING PRACTICES AND PRODUCTION OF \\ ARGUMENTATIVE TEXTS
}

\section{Lauro Gomes*}

Pontifícia Universidade Católica do Rio Grande do Sul, Porto Alegre, RS, Brasil

\begin{abstract}
Resumo: Este trabalho destina-se a apresentar uma proposta de avaliação de leitura e produção de textos dissertativo-argumentativos, com base em princípios e conceitos postos à disposição pela teoria da Argumentação na Língua (ANL), criada por Jean-Claude Anscombre e Oswald Ducrot, especialmente pela versão da Teoria dos Blocos Semânnticos (TBS) e por trabalhos nela inspirados, cujos critérios sejam capazes de envolver menos intuiç্̃ão no julgamento de desempenhos em leitura e produção de texto dissertativo-argumentativo. A análise do corpora - constitúído pela proposta de redaç̃óo do Enem 2011 e por 50 (cinquenta) redaç̃oes produzidas a partir dela $-\mathrm{e} 0$ teste dos critérios de avaliação de leitura e escrita propostos neste trabalho revelaram funcionalidade prática e eficiente dos critérios, com potencial que permite aplicá-los em qualquer processo de avaliação de texto dissertativo-argumentativo. Por fim, este trabalho também fornece subsídios teórico-metodológicos que podem auxiliar professores da educação básica e da superior a qualificar suas práticas de ensino de leitura, escrita e avaliação dos textos dos estudantes.
\end{abstract}

Palavras-chave: Semântica; Argumentação na Língua; Avaliaçãó; Redação; Texto dissertativo-argumentativo.

Abstract: This paper aims to present an evaluation proposal of the performance in reading and writing dissertative-argumentative texts, based on principles and concepts from the theory of Argumentation in Language - created by Jean-Claude Anscombre and Oswald Ducrot, especially the version of the Theory of the Semantic Blocks and the works inspired by it. The goal is to create criteria which are capable of being less intuitive in judging the performance in reading and wrinting dissertative-argumentative texts. The analysis of the corpora - the Enem 2017 's composition proposal and 50 (fifty) texts written by the students - and the test of the criteria of reading and writing evaluation in this work revealed practice funcionality and efficiency of criteria. The results allow these criteria to be applied in any evaluation processes of dissertative-argumenative texts. Finally, this paper offers theoretical and methodological subisdies which can help teachers and professors to qualify their teaching of reading and writing and the evaluation of student's texts.

Keywords: Semantic; Argumentation in language; Evaluation; Writing; Dissertative-argumentative texts.

* Doutorando em Linguística e Letras pela Pontifícia Universidade Católica do Rio Grande do Sul - PUCRS, Porto Alegre, RS, Brasil, sob orientação da Profa. Dra. Leci Borges Barbisan, CNPq; lauro.gomes.001@acad.pucrs.br 
Linha D'Água (Online), São Paulo, v. 29, n. 2, p. 295-319, dez. 2016

\section{Introdução}

Levando-se em conta a grande quantidade de textos para avaliar nas bancas examinadoras de redação de avaliações externas, como Exame Nacional do Ensino Médio (Enem), e de processos seletivos, como vestibulares, a avaliação textual impõe-se como um desafio, especialmente porque deve ser feita por mais de um avaliador e as discrepâncias entre as notas atribuídas por um e por outro - nos critérios que envolvem maior grau de subjetividade, como os que examinam desempenhos em leitura, - são recorrentes. Diante disso, este trabalho propõe-se a apresentar e testar uma proposta de avaliação de leitura e produção de textos dissertativo-argumentativos, com base nos pressupostos teóricos da Argumentação na Língua (ANL), criada por Jean-Claude Anscombre e Oswald Ducrot (1983), principalmente em princípios e conceitos postos à disposição pela Teoria dos Blocos Semânticos (TBS), atualmente desenvolvida por Marion Carel e Oswald Ducrot na França.

Para tanto, a partir da análise da proposta de redação do Enem 2011, apresenta-se um quadro com seis critérios, que - baseados na ANL/TBS - integram e modificam as competências II (Compreender a proposta de redação e aplicar conceitos das várias áreas do conhecimento para desenvolver o tema dentro dos limites estruturais do texto dissertaivo- argumentativo) e III (Selecionar, relacionar, organizar e interpretar informações, fatos e argumentos em defesa de um ponto de vista $)^{1}$ da redação do Enem. Em seguida, testa-se a funcionalidade de tais critérios em 50 (cinquenta) redações do Enem 20112. Avaliam-se, por ocasião do teste dos critérios, os níveis de desempenho do participante em leitura e produção escrita de texto, a saber: a) o entendimento da ideia central da proposta de redação; b) a capacidade de construir essa ideia central dentro dos padrões composicionais do texto dissertativo-argumentativo e c) a capacidade de desenvolver argumentos capazes de fugir às ideias generalizantes, que normalmente repetem o senso comum.

A análise da proposta de redação e o teste dos critérios de avaliação de leitura e escrita propostos neste trabalho revelaram funcionalidade prática e eficiente dos

\footnotetext{
1 Confiram-se as cinco competências avaliadas na redação do Enem no Guia do Participante (ENEM, 2013).

2 Todas as redações da amostra, que foi disponibilizada pelo Inep (2014) para esta pesquisa, foram avaliadas no Enem 2011 dentro do intervalo de regular a excelente [500-1000].
} 
Linha D'Água (Online), São Paulo, v. 29, n. 2, p. 295-319, dez. 2016

critérios, com potencial que permite aplicá-los em qualquer processo de avaliação de texto dissertativo-argumentativo. Por fim, este trabalho também fornece subsídios teórico-metodológicos que podem auxiliar professores da educação básica e da superior a qualificar suas práticas de ensino de leitura, de escrita e, sobretudo, de avaliação dos textos dos estudantes.

\section{Ferramentas da ANL/TBS para avaliação de leitura e de escrita}

A teoria da Argumentação na Língua (ANL), sobretudo na fase da Teoria dos Blocos Semânticos (TBS), fornece subsídios linguísticos para avaliar, com mais segurança, o desempenho do participante na leitura dos textos da proposta de redação e na produção do texto dissertativo-argumentativo, uma vez que, amparando-se estritamente na língua, permite reduzir intuição e subjetividade provocadoras de dúvidas e discrepâncias na avaliação.

A Semântica Argumentativa de Oswald Ducrot e colaboradores defende que as palavras da língua não têm sentido completo antes das continuações que se podem extrair delas. Quando se comparam enunciados como (1) Faz calor, vamos passear e (2) Faz calor, não vamos passear (DUCROT, 1990, p. 73), nota-se que o valor semântico de calor não é o mesmo. Em 1, os segmentos A: Faz calor e B: vamos passear constituem, segundo Ducrot (1990), um só enunciado, visto que A só tem sentido em relação a $\mathrm{B}$ e vice-versa.

Segundo essa semântica linguística, as palavras da língua já contêm orientações argumentativas que autorizam certas continuações discursivas e vetam outras. Por isso, de acordo com essa perspectiva teórica, pode-se perceber que os próprios enunciados que constituem os discursos de uma proposta de redação, por exemplo, orientam certos percursos argumentativos para o participante percorrer na sua redação e vetam outros. Conforme elucida Barbisan (2013), foi amparado no conceito de valor de Saussure que Ducrot (1990), buscando rechaçar a existência de um aspecto objetivo na linguagem ordinária, unificou os aspectos subjetivo e intersubjetivo no que chamou de valor argumentativo - nível fundamental da descrição semântica. Esse valor argumentativo, definido como um conjunto de possibilidades ou impossibilidades de continuação discursiva que o emprego de uma 
palavra determina, reforça que o uso da língua é um exercício de intersubjetividade e que a apreensão dos fatos do mundo é sempre argumentativa.

Numa das fases mais atuais da ANL, a TBS, Marion Carel e Oswald Ducrot (2005) propuseram-se a considerar como argumentativas as relações semânticas normativas em donc - realizadas implícita ou explicitamente por conectores do tipo de portanto, se ou ainda porque - e as transgressivas em pourtant - realizadas implícita ou explicitamente por conectores do tipo de no entanto, mesmo se, ou ainda apesar de que - entre um signo e outro. O sentido das entidades linguísticas, segundo os referidos autores (2005, p. 13), "não se constitui por coisas, fatos, propriedades, crenças psicológicas, nem ideias, mas por certos discursos que a entidade linguística evoca". Esses discursos, denominados de encadeamentos argumentativos, constituem intralinguisticamente o sentido e, de acordo com Carel (2013), estão na base de todas as construções semânticas.

Considerando-se um encadeamento argumentativo X CON Y, pode-se denominar A o segmento X e B, o segmento Y. Tomando-se como exemplo o encadeamento (3) O hotel está perto da Universidade, portanto é fácil chegar., Carel e Ducrot $(2005$, p. 20) chamam A para perto e B para fácil chegar. Admitida essa convenção, os referidos autores definiram a noção de aspecto argumentativo. Convencionaram chamar A DC B de aspecto, visto que ele representa um conjunto de encadeamentos argumentativos normativos X DC Y. Desse modo, notaram que um aspecto A DC B contém, entre outros, encadeamentos como (3) O hotel está perto da Universidade, portanto é fácil chegar., (4) A Catedral está perto da Faculdade, portanto é fácil chegar. e (5) Meu dormitório está perto do teu, portanto é fácil chegar, uma vez que, em todos os casos, o pertinente é A, perto, e B, fácil chegar.

A interdependência semântica que se estabelece entre os dois segmentos de um encadeamento argumentativo dá origem a um bloco semântico. Assim, pode-se notar que, nos enunciados (6) Há um verdadeiro problema, portanto o deixemos de lado. e (7) Há um verdadeiro problema, no entanto não o deixemos de lado., o bloco semântico que esses discursos imprimem relaciona dificuldadel postergar. E, conforme explicam Ducrot e Carel (2005), a relação semântica entre os segmentos $\mathrm{A}$ e $\mathrm{B}$ desses encadeamentos permite construir oito aspectos argumentativos, 
Linha D'Água (Online), São Paulo, v. 29, n. 2, p. 295-319, dez. 2016

organizados em dois blocos de quatro aspectos cada um. O bloco semântico (1) relaciona os aspectos:

(1) DIFICULDADE PT NEG-POSTERGAR

(2) NEG-DIFICULDADE PT POSTERGAR

(3) NEG-DIFICULDADE DC NEG-

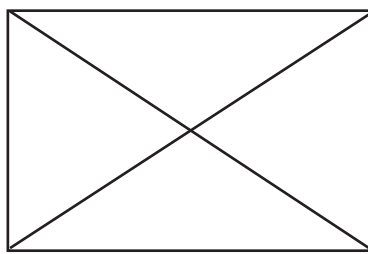

POSTERGAR

Figura 1: BS - relaciona dificuldade e postergar

Fonte: figura fundamentada em Carel e Ducrot (2005)

e o bloco semântico (2), também formado de quatro aspectos, relaciona:

(1) DIFICULDADE PT POSTERGAR

(3) NEG-DIFICULDADE DC POSTERGAR

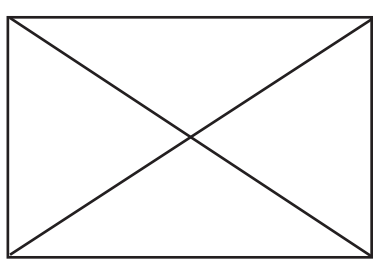

(2) NEG-DIFICULDADE PT NEG-

POSTERGAR

(4) DIFICULDADE DC NEG-POSTERGAR

Figura 2: BS2 - relaciona dificuldade e não postergar

Fonte: figura fundamentada em Carel e Ducrot (2005)

Diante disso, o sentido ou significação ${ }^{3}$ de uma entidade linguística, para a TBS, constitui-se por aspectos que lhe estão associados. Ademais, segundo destaca Carel (2012), a TBS distingue duas maneiras de ligações entre um termo e os aspectos argumentativos que ele significa. Isso revela que essa distinção - que, conforme a autora, está relacionada ao estudo argumentativo das "frases sintáticas" - deve ocorrer em virtude de que o vínculo existente entre os enunciados e as entidades semânticas tanto pode ser interno como externo. Nas palavras de Carel e Ducrot (2005, p. 65), a argumentação externa (AE) de uma entidade linguística é constituída pelos encadeamentos argumentativos que chegam à entidade ou que

3 Nessa fase de desenvolvimento da ANL, Carel e Ducrot (2005) não distinguem sentido de significação. 
partem dela. Partem da palavra prudente, por exemplo, encadeamentos como (8) Pedro é prudente, portanto não terá acidentes e (9) Pedro é prudente, portanto estará seguro. Também se encontram formando a $\mathrm{AE}$ de prudente encadeamentos que chegam até prudente, como é o caso de (10) Tem medo, portanto é prudente.

Duas propriedades da AE que a distinguem de uma argumentação interna (AI) são o fato de que a própria entidade linguística forma parte dos encadeamentos externos que a descrevem e o de que os aspectos pertencentes à $\mathrm{AE}$ existem sempre em pares. Se houver na AE de uma entidade o aspecto PRUDENTE DC SEGURANÇA, por exemplo, haverá, também, PRUDENTE PT NEG-SEGURANÇA, uma vez que, segundo Carel e Ducrot (2005), cada aspecto em DC está associado a um aspecto em PT mais NEG. Além disso, essa argumentação também pode ser $\grave{a}$ direita e à esquerda. A AE à direita de $e$ é do tipo [e CON X], como PRUDENTE DC SEGURANÇA, e a AE à esquerda é do tipo [X CON $e$ ], por exemplo TEM MEDO DC É PRUDENTE e NEG-TEM MEDO PT É PRUDENTE.

Já a argumentação interna (AI) - vínculo interno existente entre enunciados e entidades semânticas - constitui-se por um certo número de aspectos aos quais pertencem os encadeamentos que parafraseiam a entidade $e$. Conforme exemplificam Carel e Ducrot (2005), pode ser a AI de prudente o aspecto PERIGO DC PRECAUÇÃO; de temeroso, NEG-PERIGO PT PRECAUÇÃO; e de inteligen$t e$, NEG-FÁCIL PT COMPREENDE.

Revisados esses princípios e conceitos da ANL/TBS, também é importante salientar, de acordo com Carel (1998), a existência de dois tipos de mas. Um, que é articulador de oposição indireta, como no enunciado (11) Pedro estudou, mas a prova era difícil e outro, considerado ambíguo - que é articulador de oposição direta como no enunciado (12) Pedro estudou, mas não foi aprovado. Notadamente, quando o mas é de oposição indireta, pode-se predicar, por meio de portanto, sobre os dois segmentos do encadeamento. Porém, quando a oposição é direta, somente se pode predicar sobre o primeiro segmento do encadeamento. Esse segundo mas é, pois, ambíguo justamente por não permitir que se predique, por meio de portanto, sobre o segundo segmento do encadeamento.

Por fim, vale destacar, de acordo com Ducrot (1999), que os atuais trabalhos em Semântica Argumentativa conciliam duas teses: a primeira, que defende a ideia 
segundo a qual os encadeamentos argumentativos constroem, por eles mesmos, representações do mundo de que se fala, excluindo, portanto, a possibilidade de haver a descrição de argumentações das representações do mundo no sentido atribuído pela retórica clássica; e a segunda tese, defensora da ideia de que os encadeamentos argumentativos restringem-se pela semântica intrínseca das palavras empregadas no discurso. Nas palavras de Ducrot (1999, p. 10), essa segunda tese "satisfaz o objetivo estruturalista da ANL, e leva a descrever as palavras, não a partir de um conhecimento prévio da realidade (o que implicaria sua descrição "informativa"), mas a partir de suas potencialidades discursivas".

\section{Análise da proposta de redação do Enem 2011}

Revisados os conceitos necessários aos propósitos deste trabalho, apresenta-se o procedimento utilizado na análise dos textos que compõem a proposta de redação do Enem 2011, composta de um parágrafo de instruções e de três textos ditos "motivadores". Aos três textos foi aplicado o procedimento que segue: (1) dividiuse o texto em trechos que constituíssem um motivo argumentativo, isto é, capazes de expressar um aspecto e de evocar um encadeamento; (2) foram identificados o encadeamento e o aspecto argumentativo que expressavam a ideia central de cada texto; (3) relacionaram-se essas ideias por meio da $\mathrm{AI}$ e da $\mathrm{AE}$ das entidades que as compõem, construindo, desse modo, a ideia central da proposta.

Antes de iniciar a análise dos textos é interessante observar que a estrutura composicional das propostas de redação do Enem está relativamente estabilizada. Tem iniciado com a apresentação e caracterização da atividade a ser realizada, seguida de mais de um texto, como se pode verificar:

Com base na leitura dos seguintes textos motivadores e nos conhecimentos construídos ao longo de sua formação, redija texto dissertativo-argumentativo em norma culta escrita da língua portuguesa sobre o tema VIVER EM REDE NO SÉCULO XXI: OS LIMITES ENTRE O PÚBLICO E O PRIVADO, apresentando proposta de conscientização social que respeite os direitos humanos. Selecione, organize e relacione, de forma coerente e coesa, argumentos e fatos para defesa de seu ponto de vista. 
Abaixo desse trecho, que fornece instruções ao estudante, relativas ao gênero em que deverá desenvolver sua redação, dissertativo-argumentativo, ao estilo de linguagem a ser utilizado no texto, a norma culta da língua portuguesa, e ao tema a ser abordado, Viver em rede no século XXI: os limites entre o público e o privado, segue o primeiro texto da proposta, intitulado Liberdade sem fio. Leia-se:

A ONU acaba de declarar o acesso à rede um direito fundamental do ser humano assim como saúde, moradia e educação. No mundo todo, pessoas começam a abrir seus sinais privados de $w i-f$, organizações e governos se mobilizam para expandir a rede para espaços públicos e regiões aonde ela ainda não chega, com acesso livre e gratuito. ROSA, G.; SANTOS, P. Galileu, n. 240, jul. 2011 (fragmento).

Desse texto evoca-se, de início, o encadeamento argumentativo normativo $[A$ ONU declara que o acesso à rede é direito fundamental, portanto pessoas, organizações e governos se mobilizam para expandir a todos com acesso livre e gratuito] ao qual se associa o aspecto argumentativo SER DIREITO FUNDAMENTAL DC TER GARANTIA DE ACESSO LIVRE E GRATUITO, que constitui a argumentação interna de liberdade de acesso, cuja expressão está diretamente relacionada ao título do texto.

Nessa direção, o sentido argumentativo do texto em foco, filtrado pela subjetividade dos estudantes, poderia servir-lhes como ponto de partida de sua redação $\mathrm{e}$, fundamentalmente, deveria perpassar seus projetos de texto.

Abaixo, apresenta-se o segundo texto da proposta, intitulado $A$ internet tem ouvidos e memória, cuja argumentação será analisada na sequência. Confira-se:

Uma pesquisa da consultoria Forrester Research revela que, nos Estados Unidos, a população já passou mais tempo conectada à internet do que em frente à televisão. Os hábitos estão mudando. No Brasil, as pessoas já gastam cerca de $20 \%$ de seu tempo on-line em redes sociais. A grande maioria dos internautas (72\%, de acordo com o Ibope Mídia) pretende criar, acessar e manter um perfil em rede. "Faz parte da própria socialização do indivíduo do século XXI estar numa rede social. Não estar equivale a não ter uma identidade ou um número de telefone no passado", acredita Alessandro Barbosa Lima, CEO da e.Life, empresa de monitoração e análise de mídias. 
As redes sociais são ótimas para disseminar ideias, tornar alguém popular e também arruinar reputações. Um dos maiores desafios dos usuários de internet é saber ponderar o que se publica nela. Especialistas recomendam que não se deve publicar o que não se fala em público, pois a internet é um ambiente social e, ao contrário do que se pensa, a rede não acoberta anonimato, uma vez que mesmo quem se esconde atrás de um pseudônimo pode ser rastreado e identificado. Aqueles que, por impulso, se exaltam e cometem gafes podem pagar caro. Disponível em : http://terra.com.br. Acesso em: 30 jun. 2011 (adaptado)

Trecho 1: Uma pesquisa da consultoria Forrester Research revela que, nos Estados Unidos, a população já passou mais tempo conectada à internet do que em frente à televisão. Os hábitos estão mudando. No Brasil, as pessoas já gastam cerca de $20 \%$ de seu tempo on-line em redes sociais.

É importante observar que a organização semântico-argumentativa desse primeiro trecho realiza-se em torno da argumentação interna (AI) de os hábitos estão mudando, constituída pelo aspecto argumentativo FAZIA X PT NEG-FAZ MAIS, à qual, de acordo com Graeff (2012), os enunciados [Uma pesquisa da consultoria Forrester Research revela que, nos Estados Unidos, a população já passou mais tempo conectada à internet do que em frente à televisão] e [No Brasil, as pessoas já gastam cerca de $20 \%$ de seu tempo on-line em redes sociais] conectam-se pelo processo de similaridade, visto que ambos funcionam como exemplos e, portanto, reiteram a AI de Os hábitos estão mudando.

Trecho 2: A grande maioria dos internautas (72\%, de acordo com o Ibope Mídia) pretende criar, acessar e manter um perfil em rede.

O julgamento argumentativo desse trecho é constituído pelo encadeamento argumentativo normativo [ser internauta, portanto criar, acessar e manter um perfil em rede] e pelo aspecto argumentativo nele expresso, SER INTERNAUTA DC TER IDENTIDADE NA REDE, que constitui uma AE de internauta.

Trecho 3: "Faz parte da própria socialização do indivíduo do século XXI estar numa rede social. Não estar equivale a não ter uma identidade ou um número de telefone no passado", acredita Alessandro Barbosa Lima, CEO da e.Life, empresa de monitoração e análise de mídias. 
Linha D'Água (Online), São Paulo, v. 29, n. 2, p. 295-319, dez. 2016

Interessante observar que esse trecho explicita um par de encadeamentos argumentativos normativos cujos aspectos do bloco semântico mantêm entre si relação de reciprocidade. O primeiro encadeamento, [estar numa rede social, portanto ter participação social], tem como aspecto expresso ESTAR EM REDE DC TER IDENTIDADE SOCIAL e o segundo, [não estar numa rede social, portanto não ter uma identidade ou um número de telefone no passado], possui como aspecto NEG-ESTAR EM REDE DC NEG-TER IDENTIDADE SOCIAL, recíproco do anterior.

Trecho 4: As redes sociais são ótimas para disseminar ideias, tornar alguém popular e também arruinar reputações. Um dos maiores desafios dos usuários de internet é saber ponderar o que se publica nela.

Desse trecho, pode-se evocar o encadeamento argumentativo [as redes sociais disseminam ideias para o bem e para o mal, portanto exigem cuidado com o que épublicado], cujo aspecto expresso é TUDO É PÚBLICO NAS REDES SOCIAIS DC PRECAUÇÃO COM O QUE SE PUBLICA, que constitui uma AI de prudência em rede. Por haver o acréscimo de uma nova $\mathrm{AI}$ no texto, nota-se que a conexão existente entre os enunciados desse quarto trecho e os que constituem o terceiro trecho ocorre por contiguidade.

Trecho 5: Especialistas recomendam que não se deve publicar o que não se fala em público, pois a internet é um ambiente social e, ao contrário do que se pensa, a rede não acoberta anonimato, uma vez que mesmo quem se esconde atrás de um pseudônimo pode ser rastreado e identificado. Aqueles que, por impulso, se exaltam e cometem gafes podem pagar caro.

Desse trecho evoca-se o encadeamento argumentativo normativo [não se fala em público, portanto não se fala na rede] cujo aspecto nele expresso, NEG-DIZÍVEL EM PÚBLICO DC NEG-DIZÍVEL EM REDE, corresponde à AI de conteúdo privado. Eis que, de acordo com o sentido do discurso em análise, vetavase a possibilidade de o aluno argumentar, por exemplo, a partir do aspecto NEG-DIZÍVEL EM PÚBLICO PT DIZÍVEL EM REDE, haja vista que é exatamente a realização desse aspecto que arruína a reputação de muitas pessoas no século XXI. Note-se, entretanto, a possibilidade de se explicitar, por meio de até, o 
Linha D'Água (Online), São Paulo, v. 29, n. 2, p. 295-319, dez. 2016

aspecto DIZÍVEL EM PÚBLICO PT NEG-DIZÍVEL EM REDE. Ocuparia este último aspecto lugar em discursos argumentativamente de excelente qualidade, os quais, além de fugirem ao senso comum, demonstrariam preocupação em propor solução para o problema. Evidentemente que o fato de se tomar precaução, evitando-se dizer em rede inclusive conteúdos que se diriam em público, fora da rede, seria propor aumentar o cuidado com o que se diz em ambientes virtuais, porque, muitas vezes, o internauta pode ser mal interpretado pelos outros usuários da rede e sofrer consequências diversas por isso.

Explicitados os aspectos do bloco semântico anteriormente referido, na sequência do discurso, evoca-se o encadeamento [é ambiente social, mesmo assim não acoberta o anonimato], que, de acordo com o que propõe Graeff (2012), conecta-se por similaridade ao encadeamento seguinte, [esconder-se atrás de um pseudônimo, mesmo assim ser rastreado e identificado], uma vez que ambos têm o mesmo aspecto expresso, É AMBIENTE PÚBLICO PT SER IDENTIFICADO, que constitui a argumentação interna (AI) de inexistência de anonimato. Por fim, o encadeamento que esse trecho permite evocar é [exaltar-se, portanto sofrer consequências], cujo aspecto expresso é DIZER O QUE NEG-DIRIA EM PÚBLICO DC SOFRER CONSEQUENNCIAS.

Chega-se à conclusão de que a ideia central desse segundo texto ${ }^{4}$, que também compreende o sentido do primeiro, pode ser resumida no aspecto argumentativo único, TER GARANTIA DE ACESSO À REDE PT NEG-SER LIVRE PARA PUBLICAR O QUE QUISER, o qual está diretamente relacionado ao tema da proposta de redação. Destaque-se que ele é transgressivo, uma vez que expressa uma exceção ao aspecto TER GARANTIA DE ACESSO À REDE DC SER LIVRE PARA PUBLICAR O QUE QUISER.

Feita a análise dos dois primeiros textos, contendo apenas linguagem verbal, confira-se o último texto da proposta, com linguagem verbal e não verbal.

4 Vale destacar que, ao longo deste trabalho, optou-se por utilizar as palavras texto e discurso como sinônimas. 
Linha D'Água (Online), São Paulo, v. 29, n. 2, p. 295-319, dez. 2016

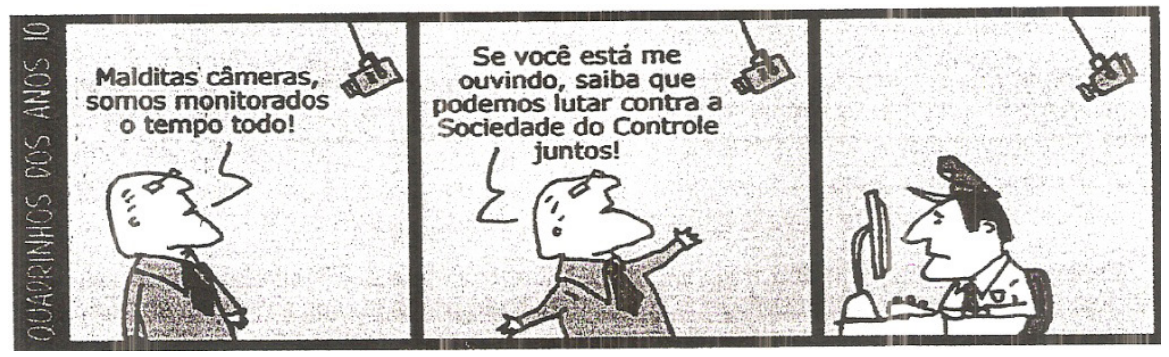

Figura 3: Quadrinhos dos anos 10

Fonte: figura retirada da proposta de redação do Enem 2011, em cujo texto explicita-se a seguinte referência: DAHMER, A. Disponível em: http://malvados.wordpress.com.

Acesso em: 30 jun. 2011.

Trecho 1: Malditas câmeras, somos monitorados o tempo todo!

O encadeamento argumentativo que esse trecho permite evocar é [ há câmeras em todo lugar, portanto ser monitorado o tempo todo], cujo aspecto expresso é HAVER CÂMERAS EM TODA PARTE DC SER SEMPRE MONITORADO, que constitui a AI de Sociedade do Controle. Observe-se, além disso, que a AI de malditas, nesse trecho, é constituída pelo aspecto argumentativo NEG-DEVERIA HAVER CÂMERAS PT HÁ.

Trecho 2: Se você está me ouvindo, saiba que podemos lutar contra a Sociedade do Controle juntos!

Da análise semântico-argumentativa dos enunciados desse segundo trecho do texto resultam dois aspectos argumentativos neles expressos: o primeiro, OUVIR DC SABER [QUE PODE LUTAR CONTRA O CONTROLE], constitui uma AI de cidadania, e o segundo, HÁ SOCIEDADE DO CONTROLE DC LUTAR CONTRA O CONTROLE, constitui uma AE de Sociedade do Controle.

Trecho 3: Apenas linguagem não verbal

Observe-se que esse terceiro trecho, contendo apenas linguagem não verbal, permite evocar o encadeamento argumentativo transgressivo, [monitorar, mesmo assim ser monitorado], ao qual se pode associar o aspecto argumentativo, já relacionado no primeiro trecho, no qual se constrói uma AI de Sociedade do Controle: HAVER CÂMERAS EM TODA PARTE DC SER SEMPRE MONITORADO.

GOMES, L. A argumentação na língua como subsídio para avaliação de leitura e produção de textos 
Desse modo, verifica-se que esse terceiro quadrinho da tira tem a função de exemplificar, por meio de imagens, o funcionamento da Sociedade do Controle, explicitando que até mesmo quem monitora é monitorado. Nessa direção, o sentido desse terceiro quadrinho, contendo apenas linguagem não verbal, é garantido pela linguagem verbal - igualmente notado por Graeff e Gomes (2014), a propósito do estudo da relação entre linguagem verbal e não verbal em tiras, pela Semântica Argumentativa.

É possível afirmar que a ideia central desse último texto da proposta de redação pode ser resumida no aspecto argumentativo HAVER CÂMERAS EM TODA PARTE DC SER MONITORADO, visto que explicita o próprio sentido de Sociedade do Controle.

Porém, é importante que se observe, aqui, o acréscimo de um novo tema à proposta de redação, uma vez que o tema Viver em rede no século XXI: os limites entre o público e o privado já está delimitado ao âmbito da internet, mais especificamente de redes sociais. Logo, não pode ter relação direta com o tema Sociedade do Controle. Acredita-se, em razão disso, que os alunos poderiam apresentar dificuldade em relacionar e, sobretudo, em articular esse último texto aos dois anteriores sem tangenciar ou até mesmo fugir ao tema proposto.

Por fim, vale ainda destacar que a ideia central da proposta de redação do Enem 2011 pode ser resumida no aspecto argumentativo transgressivo TER LIBERDADE ILIMITADA DE INTERAÇÃO PT TER DE LIMITAR O QUE PUBLICA EM REDE, cujo bloco semântico relaciona ter liberdade ilimitada de interação e ter de limitar o que se publica em rede. O primeiro segmento, notadamente, corresponde à ideia central do primeiro texto, e todo o encadeamento corresponde à ideia central do segundo texto.

\section{Critérios para avaliação de leitura e produção de textos dissertativo-argumentativos}

Explicitadas as ideias centrais dos textos da proposta de redação e, por fim, a ideia central de toda a proposta, apresentam-se, nesta seção, os critérios elaborados, com base na ANL, para avaliar a leitura e a produção do texto solicitado, especialmente 
Linha D'Água (Online), São Paulo, v. 29, n. 2, p. 295-319, dez. 2016

sua organização semântico-argumentativa. Numa amostra de 50 (cinquenta) redações do Enem 2011, esses critérios foram testados com o intuito de avaliar o desempenho do participante em relação à leitura dos textos que permitem entender o tema da proposta e à sua capacidade de organizar as ideias dentro dos padrões composicionais do texto dissertativo-argumentativo.

No entanto, antes de passar à explicitação do quadro dos critérios de avaliação, é essencial definir, de acordo com o que propõem Graeff, Bernardi e Gomes (2014), os critérios de entendimento, tangenciamento e fuga de tema, tomando-se por base a ideia central da proposta de redação em foco.

Considera-se haver entendimento do tema, quando há explicitação dos dois segmentos que compõem o referido aspecto; tangenciamento, quando apenas um dos segmentos é explicitado, e fuga ao tema, quando nenhum segmento é contemplado no texto, ou um deles é associado à prevenção de catástrofes, por exemplo. Um participante que apresenta argumentação centralizada na ideia de que, no século XXI, as pessoas têm acesso ilimitado de interação em rede, mas precisam saber limitar o que publicam nela, notadamente demonstra entendimento do tema proposto. Porém, aquele que centraliza sua argumentação na ideia de que, no século XXI, as pessoas têm acesso ilimitado de interação em rede ou, apenas focaliza argumentação sobre a ideia da existência de limites impostos sobre o que se publica em rede, é um texto que tangenciará o tema; já aquele que não contempla a ideia de que, no século XXI, as pessoas têm acesso ilimitado de interação em rede e tampouco reconhece a ideia de que existem limites impostos sobre o que se pode publicar na rede é um texto que foge ao tema.

Nessa direção, o participante poderia desenvolver a ideia central da proposta de redação, relacionando algumas das ideias contidas nos próprios textos que constituem a proposta. Para desenvolver o primeiro segmento, TER LIBERDADE ILIMITADA DE INTERAÇÃO, seria possível desenvolver, por exemplo, os encadeamentos argumentativos [ser direito fundamental DC ter garantia de acesso livre e gratuito], [estar em rede DC ter identidade social] e [fazia X PT neg-faz mais]. Da mesma forma, para desenvolver o segundo segmento, TER DE LIMITAR O QUE PUBLICA, o participante poderia explicitar sentidos como [inexistência de privado DC precaução], [neg-dizivel em público DC neg-dizivel em rede], [dizer o que neg-diria em público DC sofrer consequências] e a própria ideia central dos textos $1 \mathrm{e}$ 
Linha D'Água (Online), São Paulo, v. 29, n. 2, p. 295-319, dez. 2016

2, [ter garantia de acesso à rede $\mathrm{PT}$ neg-ser livre para publicar o que quiser]. Em vista disso, considera-se já haver compreensão dos segmentos, quando há explicitação dos sentidos das palavras "liberdade" e "limite" em rede.

Considerando a matriz de avaliação da redação do Enem, reúnem-se, neste trabalho, as competências II e III numa só, denominada Identificar a ideia central da proposta de redação e produzir um texto, usando estratégias linguístico-discursivas próprias à constituição de texto dissertativo-argumentativo. Observe-se que essa competência avalia fundamentalmente três aspectos, a saber: (1) capacidade de leitura dos textos que constituem a proposta de redação; (2) capacidade de relacionar as ideias centrais de cada texto da proposta e de construir a ideia central da proposta de redação dentro dos padrões composicionais do texto dissertativo-argumentativo e (3) qualidade dos argumentos utilizados 5 . Portanto, trata leitura e escrita como um processo enunciativo único. Ler, segundo essa concepção, significa o locutor resgatar os sentidos produzidos pelo interlocutor, e escrever significa o locutor produzir sentidos para serem resgatados pelo interlocutor.

Para que haja desempenho satisfatório no primeiro e no segundo aspecto avaliados, é fundamental que o participante faça uma boa leitura dos textos da proposta de redação, de modo que, pelo estabelecimento de relação entre essas ideias, explicite a ideia central de cada texto e, por fim, a ideia central da proposta. Como visto na descrição semântica dos textos da proposta, cada texto possui uma ideia central, isto é, um bloco semântico principal, em relação ao qual se relacionam outras ideias, que são blocos semânticos secundários.

No que se refere à construção da ideia central da proposta no padrão dissertativo-argumentativo, considera-se que respeita tal estrutura aquele texto que possui as seguintes características: (1) possui uma introdução, que apresenta o tema e predispõe-no à aceitação da tese; expóe fatos, dando a conhecer essa tese; expõe argumentos, para defender uma opinião ou ir contra os argumentos da parte contrária, e uma conclusão, que recapitula ideias essenciais do texto e apresenta uma nova

5 Entenda-se por "qualidade dos argumentos" a capacidade de desenvolver ideias que fogem do senso comum. Na sequência desta seção, pode-se verificar que a referida "qualidade" é avaliada pela linguagem verbal, na medida em que examina, com base na $A N L$, se os "argumentos" repetem ideias de senso comum ou as transgridem. Desse modo, crê-se diminuir aquela subjetividade que provoca discrepância.

GOMES, L. A argumentação na língua como subsídio para avaliação de leitura e produção de textos 
tese; e (2) possui um nível justificativo - no qual o interlocutor é pouco levado em conta - e/ou um nível dialógico ou contra-argumentativo - em que a argumentação é negociada com um contra-argumentador real ou potencial.

Em vista disso, estarão construídos em padrões embrionários de texto dissertativo-argumentativo aqueles textos que infringirem as referidas características de forma da dissertação. Por exemplo, textos que são construídos em parágrafo único, sem fazer a separação de introdução, exposição de fatos e argumentos (desenvolvimento) e conclusão ou que não explicitam uma tese (anterior), argumentos, uma antítese (no nível contra-argumentativo) e uma (nova) tese na conclusão.

Em relação ao terceiro aspecto avaliado, a qualidade dos argumentos, saliente-se que são, em geral, considerados de senso comum aqueles enunciados ou partes do texto que permitem evocar encadeamentos argumentativos normativos, em donc (portanto), generalizações como [É rico, portanto é feliz], [Trabalha, portanto ganha dinheiro], [É político, portanto é corrupto], etc. Os argumentos desenvolvidos de maneira mais qualificada são, em geral, aqueles de cujos enunciados evocam-se encadeamentos transgressivos, em pourtant (no entanto/ mesmo assim), como [É rico, mesmo assim não é feliz], [Trabalha, no entanto não ganha dinheiro], [É politico,mas não é corrupto], etc.

Vale destacar que a concessão apresenta significativas vantagens no discurso persuasivo, uma vez que permite ao locutor melhorar a imagem de si. Construída num nível dialógico, essa estratégia argumentativa também garante alteridade ao discurso. Desse modo, cumprindo também uma característica do padrão dissertativo-argumentativo, considera-se que deve receber nota máxima na avaliação de desempenhos em leitura e produção de texto dissertativo-argumentativo aquele em que a estratégia concessiva é utilizada adequadamente.

Para que melhor se compreenda como a estratégia concessiva poderia ter sido utilizada pelo estudante na sua redação, a partir da proposta de redação em foco, imaginem-se, primeiramente, - conforme elucida Ducrot (2009) - argumentos de um locutor L2, contrários à tese de que as redes sociais são positivas, os quais poderiam ir de encontro a uma argumentação de um L1 que se propusesse a defendê-la. Serviriam de argumentos enunciados do tipo de (1) As redes sociais não asseguram o anonimato e (2) As redes sociais oferecem riscos de exposição a seus usuários. 
Linha D'Água (Online), São Paulo, v. 29, n. 2, p. 295-319, dez. 2016

Explicitados esses dois enunciados possíveis na constituição de contra-argumentos, poder-se-ia sugerir que o estudante/participante desenvolvesse seu parágrafo num nível dialógico, organizado da seguinte forma: Embora as redes sociais não assegurem o anonimato de seus usuários e até lhes ofereçam riscos de exposição, há que se reconhecer que elas são ótimas para disseminar ideias, [...].

Assim estruturado, o parágrafo resultaria de um diálogo entre o L1 e o L2 e a imagem que o L1 constituiria de si no discurso seria de alguém que aceita a discussão, haja vista que - por considerar os pontos de vista de seu interlocutor - acredita-se ser alguém que não procura impor-se brutalmente. Explicitada a concessão do parágrafo, restaria ao participante desenvolvê-lo, utilizando-se de justificativas capazes de fundamentar a tese a ser defendida.

Confiram-se, no quadro de avaliação aqui apresentado, os critérios estabelecidos para avaliar o desempenho do participante na leitura da proposta de redação e na produção do texto dissertativo-argumentativo: 


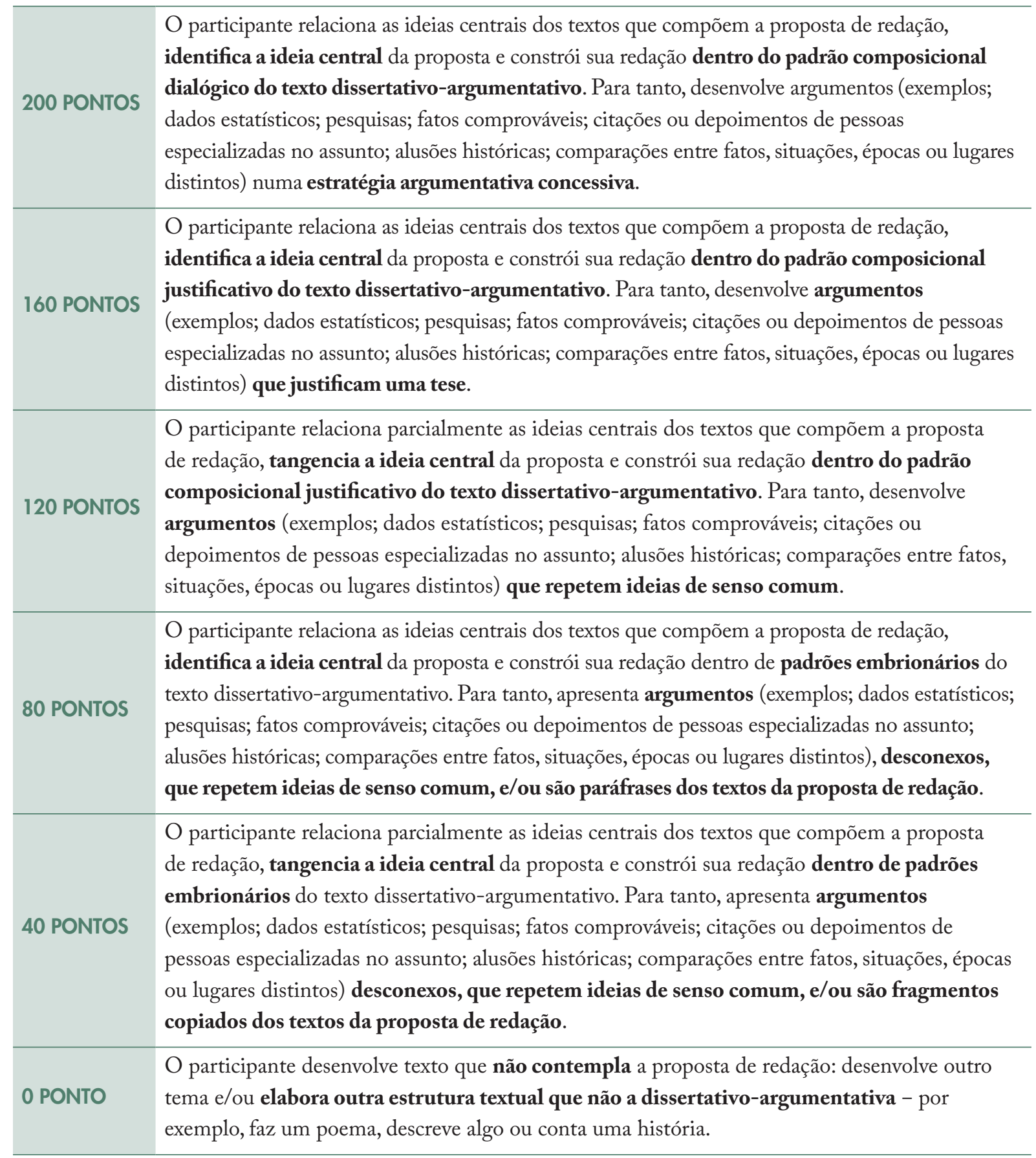

Quadro 1: Proposta de avaliação de leitura e produção de textos dissertativo-argumentativos

Fonte: quadro criado por Gomes (2014)

Nota: Este quadro fundamenta-se na ANL, especialmente em ferramentas postas à disposição pela TBS, em trabalhos nela inspirados e nas concepções de sequência argumentativa (cf. ADAM, 2011) e de estrutura da dissertação (cf. RIFO; ALVORADO, 2003). 
Dos critérios atuais de avaliação da redação do Enem, mantiveram-se os três seguintes aspectos: (1) os tipos de argumento propostos pelo Guia do Participante (INEP, 2013, p. 17), a saber, exemplos; dados estatísticos; pesquisas; fatos comprováveis; citaçôes ou depoimentos de pessoas especializadas no assunto; alusões históricas; comparações entre fatos, situações, épocas ou lugares distintos, os quais, no entanto, são denominados, no referido Guia, como estratégias argumentativas; (2) os seis níveis de pontuação - que avaliam as redações dentro do intervalo de [0 - 200] pontos - e (3) o critério que desclassifica o participante, o de nota zero.

Desse modo, a proposta de avaliação aqui apresentada é coerente com o propósito da prova de redação das avaliações externas e dos vestibulares, que, em especial, é examinar desempenhos linguístico-discursivos dos estudantes, suas competências e habilidades de leitura e produção de texto, não simplesmente, e sobretudo, seus conhecimentos a respeito de um tema. De acordo com Inep (2006, p. 44, grifo do autor), "na redação ou produção de texto, o participante é considerado como escritor, autor de um texto que atende à proposta feita por outros interlocutores”. Além disso, o referido Relatório Pedagógico do Enem salienta haver, na redação, um projeto de texto cujos limites são "a língua escrita”, "o tipo de texto dissertativo-argumentativo" e "o tema".

Acredita-se que este trabalho qualifica as competências II e III do Enem, destinadas à avaliação de leitura e produção texto, especialmente porque: (1) permite avaliar desempenhos em leitura e escrita, envolvendo menos subjetividade do avaliador; (2) fundamenta a avaliação da leitura e da escrita de texto dissertativo -argumentativo com base numa semântica linguística com significativo potencial para melhorar, inclusive, a qualidade do ensino de redação na escola, e (3) não separa a avaliação de desempenhos em leitura e escrita.

O primeiro passo rumo à constituição de uma proposta de redação adequada é a explicitação de diferentes textos que versem sobre o mesmo tema; que explicitem, contudo, pontos de vista diferentes. Desse modo, o texto do estudante/ participante resultará de um debate instalado nos textos da própria proposta e não ficará subordinado aos conhecimentos prévios do aluno. Esse posicionamento apresenta como vantagens não só a possibilidade de se realizar uma avaliação segura, envolvendo menos intuição do avaliador, mas também o fato de possibilitar 
um tratamento igual para todos, na medida em que, oferecendo os conhecimentos suficientes para que o participante construa sua argumentação, reduzem-se as disparidades socioeconômico-culturais que existem de forma tão alarmante no Brasil.

Tendo adquirido as ferramentas linguístico-discursivas necessárias à construção de texto dissertativo-argumentativo ao longo da educação básica, os estudantes/participantes são instigados, nos textos que constituem a proposta de redação, a participar de um debate nela instalado e, posteriormente, são avaliados a partir de conhecimentos comuns para todos. Esse esclarecimento é essencial, pois não restam dúvidas de que quanto menor for o "debate" de pontos de vista colocado à disposição na proposta de redação dos Exames, maiores serão as possibilidades de alunos mais favorecidos social e culturalmente terem melhores desempenhos do que aqueles que possuem menores condições socioeconômico-culturais.

\section{Conclusão ${ }^{6}$}

Testados os critérios na amostra de redações ${ }^{7}$, foi interessante observar a incidência de 23 textos (46\%) no critério de 80 pontos, pois, nesse critério, os participantes demonstram identificação da ideia central da proposta, mas não observam os padrões composicionais de texto dissertativo-argumentativo, desenvolvendo argumentos desconexos, que repetem ideias de senso comum, e/ou que são paráfrases dos textos da proposta de redação.

6 Este trabalho resultou da dissertação de Mestrado de Lauro Gomes, intitulada Avaliação de leitura e produção de textos dissertativo-argumentativos pela teoria da Argumentação na Língua, orientada por Telisa Furlanetto Graeff, defendida no PPG Letras da Universidade de Passo Fundo, em 2014.

7 Vale destacar que as redações analisadas por Gomes (2014) não foram anexadas neste trabalho, pois a ética em pesquisa não autoriza torná-las públicas na íntegra. Para trabalhar com a referida amostra de redações, o pesquisador firmou acordo com o Inep, comprometendo-se de não explicitar publicamente nenhuma redação na íntegra, mesmo que em excertos, ao longo do trabalho. Por ocasião do trabalho de Gomes (2014), tiveram acesso aos textos na íntegra apenas o pesquisador e sua orientadora - quem teve por responsabilidade última conferir e validar o fichamento e as avaliações por ele realizadas - com base no cotejo dos critérios de avaliação propostos na seção 3 deste trabalho com as cinquenta (50) redações examinadas. Com o término da pesquisa, destruíram-se os referidos textos, para que, de nenhuma forma, em qualquer tempo, o sigilo requerido pudesse ser violado. 
Esse dado mostra que o desempenho insatisfatório desses participantes é, acima de tudo, na organização textual, uma vez que eles obtiveram desempenho satisfatório na leitura dos textos da proposta e insatisfatório na escrita do texto dissertativo-argumentativo. Evidentemente que - faltando as instruções necessárias sobre a estrutura interna do texto, mais especificamente sobre a possibilidade de construir sequência argumentativa em padrão justificativo ou dialógico; de argumentar normativa e/ou transgressivamente, e também de defender ideias próprias - o participante fica sujeito a escrever livremente, sem preocupação com o modo de desenvolvimento do discurso e tampouco com a qualidade dos argumentos.

Também foi bastante expressivo o número de 10 textos (20\%) avaliados com 40 pontos, visto que, nessa pontuação, o participante relaciona parcialmente as ideias centrais dos textos da proposta de redação, tangencia a ideia central da proposta e constrói sua redação em padrões embrionários do texto dissertativo-argumentativo. Conforme já apresentado no quadro da seção anterior, os argumentos, nesse caso, são desconexos, repetem ideias de senso comum e/ou são fragmentos copiados dos textos da proposta. Em vista disso, diferentemente dos participantes avaliados com 80 pontos, os que foram avaliados com 40 também apresentam desempenho insatisfatório na leitura dos textos da proposta, o que revela que a educação básica está deixando falhas também no ensino de leitura, corroborando dados de testes nacionais e internacionais sobre o desempenho em leitura.

Por fim, não se poderia deixar de destacar que 3 textos (6\%) fugiram do tema, visto que não explicitaram nenhum dos segmentos do aspecto argumentativo que constitui a ideia central da proposta de redação. Entretanto, como a amostra de redações utilizada neste trabalho já fora avaliada pelos examinadores do Inep, numa escala de regular a excelente, - com base nos critérios atuais de avaliação da redação do Enem - a existência desses textos avaliados com nota zero (0) indicia que as competências II e III necessitam de revisão.

Não se pode deixar de salientar, ainda, que uma das causas de tangenciamento e de fuga dos participantes à ideia central da proposta de redação está diretamente relacionada ao acréscimo de tema que há com o terceiro texto, Quadrinhos dos anos 10, uma vez que as orientações argumentativas autorizadas por ele dizem respeito ao tema Sociedade do Controle. Portanto, não se relacionam à ideia central da 
Linha D'Água (Online), São Paulo, v. 29, n. 2, p. 295-319, dez. 2016

proposta, TER LIBERDADE ILIMITADA DE INTERAÇÃO PT TER DE LIMITAR O QUE PUBLICA, cuja delimitação é "Viver em rede no século XXI: os limites entre o público e o privado".

Dessa forma, pôde-se observar que um percurso argumentativo que os participantes realizaram na redação - o qual culminou no tangenciamento do tema - realizou-se por meio da explicitação de argumentos relacionados à Sociedade do Controle. Evidentemente que não se poderia descartar a hipótese de haver textos que, embora explicitassem exemplos de ideias relacionadas à Sociedade do Controle, desenvolvessem o tema. Foi o que ocorreu no texto 13, por exemplo, e o que não ocorreu em 9 . Ambos foram avaliados, nesta pesquisa, com 120 pontos, sendo que o texto 9 deteve-se na explicitação da existência de equipamentos eletrônicos responsáveis por monitorem as pessoas em sociedade, e o texto 13 foi o único do corpora que conseguiu efetuar conexão entre monitoramento e presença na rede.

A título de esclarecimento, um encadeamento argumentativo que é desenvolvido ao longo do texto 9 é [haver monitoramento, portanto haver segurança], cujo aspecto nele expresso é MONITORAMENTO DC SEGURANÇA, exemplificado com a ideia do monitoramento em creches, o qual possibilita aos pais acompanhar a educação de seus filhos por meio de câmeras, etc. O texto 13, diferentemente, explicita o encadeamento argumentativo normativo [estar em rede, portanto ser vigiado o tempo todo], o que significa que o tangenciamento não ocorreu em razão da menção do monitoramento. Logo, esse texto foi avaliado como caso de tangenciamento, visto que não explicitou o segundo segmento do aspecto que constitui a ideia central da proposta, TER DE LIMITAR O QUE PUBLICA.

Embora a qualidade dos argumentos desenvolvidos nesses dois textos tenha sido insatisfatória, percebeu-se que os participantes que os escreveram têm bom conhecimento linguístico e de organização textual. Faltaram-lhes subsídios teóricos capazes de auxiliá-los a atingir os sentidos mais profundos dos textos da proposta de redação. Aos participantes, produtores de textos como o de número 13, faltou a consciência necessária de que ler bem um texto - buscando identificar a sua ideia central - significa fazer o percurso contrário ao de sua produção. Eis que, para essa habilidade ter sido bem desenvolvida, teria sido essencial a escola ter-se fundamentado na indissociabilidade da leitura e da escrita. 
Linha D'Água (Online), São Paulo, v. 29, n. 2, p. 295-319, dez. 2016

Para finalizar esta pesquisa, ressalte-se a importância de os professores conhecerem e empregarem a ANL/TBS no ensino de leitura e escrita e de a utilizarem para fundamentar mais adequadamente os processos de avaliação de redações de testes em larga escala e de processos seletivos, assegurando aos participantes uma avaliação mais justa, igual para todos.

\section{Referências}

ADAM, Jean-Michel. A linguística textual: introdução à análise textual dos discursos. 2. ed. revista e aumentada. Revisão técnica de João Gomes da Silva Neto. São Paulo: Cortez, 2011.

ANSCOMBRE, Jean-Claude; DUCROT, Oswald. L'Argumentation Dans la Langue. Bruxelles: Mardaga, 1983.

BARBISAN, Leci Borges. Do signo ao discurso: a complexa natureza da linguagem. In: FIORIN, José Luiz; FLORES, Valdir do Nascimento; BARBISAN, Leci Borges. Saussure: a invenção da Linguística. São Paulo: Contexto, 2013.

CAREL, Marion. Pourtant: argumentation by exception. Journal of Pragmatics, v.24, p. 167-188, 1995.

Argumentación normativa y argumentación exceptiva. In: Signo छ Seña, Buenos Aires, UBA, n. 9, p. 255-422, jun. 1998.

Introduction. In: CAREL, M. (Org.).Argumentation et polyphonie: de Saint Augustin à Robbe-Grillet. Paris: L'Harmattan, 2012. p. 7-58.

Tu serás um homem, meu filho. Um prolongamento da doxa: o paradoxo. Desenredo, Passo Fundo, Ed. da Universidade de Passo Fundo, v. 9, n. 2, p. 254-270, jul./dez. 2013.

; DUCROT, Oswald. La semántica argumentativa: una introducción a la teoría de los bloques semánticos. Tradução: María Marta Negroni e Alfredo M. Lescano. Buenos Aires: Colihue, 2005. 
Linha D'Água (Online), São Paulo, v. 29, n. 2, p. 295-319, dez. 2016

DUCROT, Oswald. O dizer e o dito. Revisão técnica da tradução Eduardo Guimarães. Campinas, SP: Pontes, 1987.

Polifonia y Argumentación. Conferencias del Seminario Teoría de la Argumentación y Análisis del Discurso. Cali: Universidad del Valle, 1990.

Os Topoi na "Teoria da Argumentação na Língua”. Revista Brasileira de Letras, São Carlos, v.1, n.1, p. 1-11,1999.

. A pragmática e o estudo semântico da língua. Letras de Hoje, Porto Alegre, v.40, n. 1, p. 9-21, mar.2005.

La sémantique argumentative peut-elle se réclamer de Saussure?. In: SAUSSURE, L. Nouveaux regards sur Saussure. Genebra: Librairie Droz S.A., 2006.

Argumentação retórica e argumentação lingüística. Letras de hoje, Porto Alegre, v.44, n.1, p. 20-25, jan/mar, 2009.

GOMES, Lauro. Avaliação de leitura e produção de textos dissertativo-argumentativos pela teoria da Argumentação na Lingua. 2014. 123 f. Dissertação (Mestrado) - Programa de Pós-Graduação em Letras da Universidade de Passo Fundo, UPF, Passo Fundo, 2014.

GRAEFF, Telisa Furlanetto. A conexão entre os enunciados no texto com base na semântica argumentativa. Desenredo, v. 8, n.2, p. 197-208, jul./dez, 2012.

; BERNARDI, P. S.; GOMES, Lauro. Definindo fuga e tangenciamento de tema com base na Teoria dos Blocos Semânticos. In: 50 Seminário Nacional de Língua e Literatura: Teoria e Ensino - Leitura, produção discursiva e multimodalidade. Anais, Passo Fundo: UPF, 2014. p. 1-15.

GRAEFF, Telisa Furlanetto; GOMES, Lauro. A relação semântica entre linguagem verbal e não verbal em tiras, com base na semântica argumentativa. Estudos da Lingua(gem). v.13, n. 1, p. 47-62, jun., 2015

INEP, Instituto Nacional de Estudos e Pesquisas Educacionais Anísio Teixeira. Exame Nacional do Ensino Médio (Enem): Fundamentação Teórico-Metodológica/Instituto Nacional de Estudos e Pesquisas Educacionais Anísio Teixeira. Brasília: O Instituto, 2005.

GOMES, L. A argumentação na língua como subsídio para avaliação de leitura e produção de textos 
Linha D'Água (Online), São Paulo, v. 29, n. 2, p. 295-319, dez. 2016

Exame Nacional do Ensino Médio (Enem): Relatório Pedagógico. Instituto Nacional de Estudos e Pesquisas Educacionais Anísio Teixeira. Brasília: O Instituto, 2006.

Exame Nacional do Ensino Médio (Enem). A redação no Enem 2013: Guia do Participante. Brasília, INEP/MEC, 2013.

RIFO, Mónica Pérez; ALVORADO, Olly Vega. Técnicas Argumentativas.1. ed. Santiago, Chile: Pontificia Universidad Católica de Chile, 2003.

SAUSSURE, Ferdinand de. Curso de Linguistica Geral. Organizado por Charles Bally e Albert Sechehaye. Tradução de Antônio Chelini, José Paulo Paes e Izidoro Blikstein. 7. ed. São Paulo: Cultrix, 1975.

Recebido em 28/08/2016.

Aprovado 16/09/2016.

GOMES, L. A argumentação na língua como subsídio para avaliação de leitura e produção de textos 